\title{
Getting mental health reform back on track: a leadership challenge for the new Australian Government
}

\section{Mental health reform requires leadership from the new federal government, alongside national goals and targets}

\begin{abstract}
Mental health is still underfunded [in 2013] and continues to be locked into hospital care... This mode of service configuration appears largely provider driven when compared, for example, with client and family priorities. David Richmond, Chair, Richmond Inquiry ${ }^{1}$
\end{abstract}

\section{History of mental health reform}

From the late 1950s, specialist mental health services started rapidly moving out of asylums. In the 1970s, this was accelerated by the human and civil rights movements. In 1983, the Richmond Report of mental health services in New South Wales provided the first coherent policy framework in Australia to underpin the process. In 1993, as Australia finalised its first National Mental Health Strategy, the Burdekin Report on the human rights of people with mental illness highlighted systemic failures in both community and institutional care.

Our report ... 20 years ago ... documented appalling violations of human rights affecting hundreds of thousands of our fellow Australians ... Australia is one of the wealthiest countries in the world - so while there were reasons, there were no justifications. Brian Burdekin, Human Rights Commissioner ${ }^{1}$

Since 1993, national reform has largely focused on shifting specialist services for people with persistent or psychotic disorders from an institutional to a community base. ${ }^{2}$ However, from 1998, the agenda widened to also include a commitment to reducing the broader social and economic impacts of anxiety, depression and substance misuse.

In 2005, the Mental Health Council of Australia and the then Human Rights and Equal Opportunity Commission (now the Australian Human Rights Commission) again detailed the failings of the full range of mental health services. ${ }^{3}$

Some of the stories we heard [from mental health care consumers and professionals] demonstrated the incredible strength of the human spirit and perseverance of mental health professionals doing the best they possibly could in the circumstances. However, it must be said that the vast majority of stories described a crumbling mental health care system that brought about anguish and desperation. Sev Ozdowski, Human Rights Commissioner ${ }^{3}$
Ian B Hickie AM, MD, FRANZCP, FASSA Professor of Psychiatry and Executive Director

Patrick D McGorry MD, PhD, FRANZCP Executive Director, ${ }^{2}$ and Professor of Youth Mental Health and Director ${ }^{3}$

Tracey A Davenport BA(Hons), eMBA Research Affiliate ${ }^{l}$

Sebastian P Rosenberg BA, MPubAdmin Senior Lecturer (Mental Health Policy) ${ }^{1}$

John A Mendoza BEd, GradDipHIthProm Adjunct Associate Professor, and Director ${ }^{4}$

Jane M Burns Founder and CEO, and VicHealth Senior

Research Fellow ${ }^{2}$

Jonathan Nicholas BA(Hons), MPH

Helen Christensen MPsych, PhD, FASSA Professor and

Executive Director ${ }^{7}$

1 Brain \& Mind Research Institute, University of Sydney, Sydney, NSW.

2 Orygen Youth Health Research Centre, Melbourne, VIC.

3 Centre for Youth Mental Health, University of Melbourne, Melbourne, VIC.

4 ConNetica Consulting, Caloundra, QLD.

5 Young and Well Cooperative Research Centre, Melbourne, VIC.

6 Inspire Foundation (Australia), Sydney, NSW.

7 Black Dog Institute, University of

New South Wales, Sydney, NSW.

ian.hickie@ sydney.edu.au

doi: 10.5694/mjal3.11207
Also in 2005, we reported on the lack of implementation of community priorities identified through extensive community consultations in $2002,{ }^{4}$ and proposed the adoption of national goals and targets to help reinvigorate the reform movement. ${ }^{5}$

Responding to the level of community disquiet, in 2006, Prime Minister John Howard and NSW Premier Morris Iemma initiated a new 5-year national reform plan to be led by the Council of Australian Governments. ${ }^{6}$ A series of new investments focused on youth mental health ${ }^{7}$ and much broader provision of psychological services ${ }^{8}$ than had been provided since 2002. ${ }^{9}$ However, during the subsequent national health reform period, Prime Minister Kevin Rudd abandoned an active push towards direct federal funding of community mental health care.

After mental health re-emerged as a policy issue in the 2010 federal election, Prime Minister Julia Gillard committed $\$ 2.2$ billion over 5 years to mental health care reform, including \$571 million to enhance care for 24000 Australians with severe and debilitating mental illness, and \$492 million to expand youth services, designed to eventually reach 72000 young people per year. This allocation of new resources to early intervention for young people with psychotic disorders was based on a strong evidence base, ${ }^{10}$ in contrast with the additional investments in coordinated care for those with persistent illness.

The Gillard government also established the National Mental Health Commission (NMHC), complementing the development of state-based commissions in Western Australia, NSW and Queensland. These new bodies reflect the community's willingness to invest in new structures to drive accountability and reporting of key health and social outcomes.

We will ... not waver from our view that governments need to agree and report on a small number of meaningful national indicators and ambitious but achievable targets. These need to concentrate and link up effort in all of the areas that help people to live contributing lives - housing, employment, education, family and social support, and physical health. Allan Fels, Chair, NMHC ${ }^{11}$

... the individual testimonies [in this report] show how people may miss out on finding the support they need ... And they reveal the consequences ... of such service failures: sometimes tragedy; more often lives lived on the margins, with reduced opportunity to pursue personal, relationship or career goals. John Feneley, Mental Health Commissioner of NSW ${ }^{1}$ 


\section{Change in community evaluation of implementation of priorities for Australian mental health reform, 2004 versus 2013}

\begin{tabular}{|c|c|c|c|c|}
\hline \multirow[b]{2}{*}{ Priorities* } & \multicolumn{2}{|c|}{ Implemented locally ${ }^{\dagger}$} & \multirow[b]{2}{*}{$\chi^{2}$} & \multirow[b]{2}{*}{$P$} \\
\hline & 2004 survey $\ddagger$ & 2013 survey & & \\
\hline Implementation of early intervention strategies nationally & $17 \%(123 / 723)$ & $7 \%(25 / 338)$ & 17.74 & $<0.001$ \\
\hline Innovative services for people with mental health and alcohol or other substance misuse disorders & $11 \%(78 / 721)$ & $9 \%(29 / 337)$ & 1.24 & 0.27 \\
\hline Develop wider spectrum of acute and community-based care settings & $12 \%(86 / 722)$ & $8 \%(27 / 336)$ & 3.61 & 0.06 \\
\hline Support for service development in rural and regional areas & $7 \%(25 / 372)$ & $1 \%(2 / 163)$ & 7.14 & $<0.01$ \\
\hline Implementation of national standards for mental health services & $16 \%(113 / 721)$ & $11 \%(37 / 334)$ & 3.95 & 0.05 \\
\hline Support for service development in poorly resourced areas & $2 \%(7 / 373)$ & $1 \%(2 / 151)$ & 0.19 & 0.66 \\
\hline Support for programs that promote attitudinal change among mental health workers & $10 \%(69 / 721)$ & $9 \%(30 / 334)$ & 0.09 & 0.76 \\
\hline Increased support for stigma reduction campaigns & $11 \%(76 / 721)$ & $10 \%(33 / 332)$ & 0.09 & 0.77 \\
\hline $\begin{array}{l}\text { Development of specific intergovernmental service agreements (eg, between health, education, } \\
\text { housing, employment and social security) }\end{array}$ & $15 \%(105 / 723)$ & $9 \%(29 / 332)$ & 6.87 & $<0.01$ \\
\hline More genuine consumer participation at regional and local service levels & $17 \%(120 / 722)$ & $8 \%(25 / 331)$ & 15.72 & $<0.001$ \\
\hline
\end{tabular}

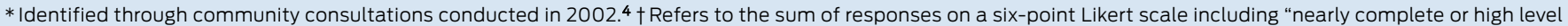

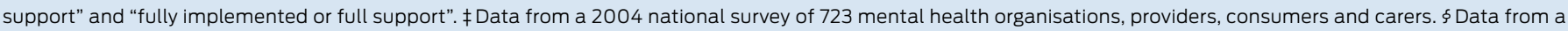
2013 national survey of 477 mental health organisations, providers, consumers and carers. ${ }^{1}$

\section{Are we making progress?}

In 2013, as part of the process of re-evaluating community perceptions of health services and developing community-based priorities for reform, we repeated the surveys (using the same methods) we had conducted in 2004. ${ }^{3,5}$ With regards to enhanced local delivery of services in each key priority area, not one area was reported as improving, and some were perceived as going backwards (Box 1). From a user's perspective, however, some other elements of care did improve (Box 2). Importantly, users reported a significant increase in access to adequate services (from 43\% to 60\%) - largely consistent with the substantive investment in Medicarefunded psychological services during this period. ${ }^{8}$

However, we have also seen a return to unacceptably high levels of seclusion and restraint in our acute care services and ongoing use of compulsory treatments in those returning to community-based care. ${ }^{1}$

... as stakeholders have emphasised [in 2010],

the system needs an overhaul to build a modern

system of mental health care in Australia ... while

improvements have been made in many areas, we

know that access to services remains uneven across

Australia, and key service gaps are evident across

all states and territories. Mark Butler, Minister for

Mental Health and Ageing ${ }^{2}$

Meanwhile, recent community surveys focusing on the needs of young people have emphasised the large degree of unmet need for care, as well as the desire to develop new ways of providing services - particularly those that are linked to new technologies. ${ }^{12}$ Importantly, people living with mental illness die at least 15 years earlier than others (largely due to premature cardiovascular disease), and this gap appears to be widening. ${ }^{13}$

\section{Challenges ahead}

In 2014, the new federal government faces major challenges in accelerating the transition to a personcentric, accessible, equitable and high-quality mental health and social services system. Some still argue for a return to the 1993-1997 focus on public services for those 100000-200000 Australians who experience the most severe, persistent or psychotic disorders. However, most international health and economic planners now accept that mental disorders affect a great many more people throughout their lives and that there is an overwhelming need for a more coordinated and responsive primary and secondary health care and social services system. ${ }^{14}$ We argue that our health and social systems need to engage people of all ages in a philosophy of recovery, respond to clinical and social need, and act to reduce life-threatening risks, irrespective of formal psychiatric diagnosis. This is certainly the perspective promoted by the NMHC. ${ }^{11}$

The challenge now is to identify those factors that are likely to be transformative and overcome many of the organisational, financial and professional barriers that have interfered with previous attempts to deliver better outcomes.

\section{Key priorities}

There needs to be a clear focus on prioritising key strategies (Box 3) and delivering specific health and economic outcomes that respond to the previously identified community priorities, ${ }^{3-5}$ new community expectations ${ }^{11}$ and the overarching governmental emphasis on enhanced social and economic participation. ${ }^{11,15}$ We have described eight key priorities, as follows:

\section{Rapid implementation of early intervention} services for young people. While these services have the capacity to be transformative, ${ }^{16}$ it is not inevitable that they will lead to improved economic, social or health outcomes. To achieve these goals, the headspace network needs to be enhanced by skilled service development, regular reporting of outcomes and clear linkage to new specialist health, employment and education services.

2. Long-term development of community-based care and real alternatives to acute hospitalisation. As 


\section{Change in consumers' and carers' direct experiences of mental health care in Australia, 2004 versus 2013*}

\begin{tabular}{|c|c|c|c|c|}
\hline & 2004 survey $^{\dagger}$ & 2013 survey ${ }^{\ddagger}$ & $\chi^{2}$ & $P$ \\
\hline To what extent were you/they treated with respect and dignity by health professionals? (always/nearly always) & $78 \%(142 / 181)$ & $83 \%(304 / 365)$ & 1.89 & 0.17 \\
\hline How much information about your/their condition or treatment was given to you? (right amount/some) & $60 \%(148 / 246)$ & $70 \%(308 / 441)$ & 6.63 & $<0.05$ \\
\hline $\begin{array}{l}\text { To what extent were you able to access adequate services for your/their mental health problems? } \\
\text { (always/nearly always) }\end{array}$ & $43 \%(74 / 171)$ & $60 \%(186 / 310)$ & 12.41 & $<0.001$ \\
\hline Did you find a health professional to talk to about your concerns? (definitely/to some extent/a little) & $81 \%(196 / 243)$ & $86 \%(373 / 434)$ & 3.25 & 0.07 \\
\hline $\begin{array}{l}\text { If your family or someone else close to you wanted to talk to a health professional, did they have enough } \\
\text { opportunity to do so? (definitely/to some extent) }\end{array}$ & $71 \%(139 / 197)$ & $75 \%(258 / 346)$ & 1.03 & 0.31 \\
\hline $\begin{array}{l}\text { How much information about your condition or treatment was given to your family or someone else close to you? } \\
\text { (right amount) }\end{array}$ & $37 \%(66 / 177)$ & $45 \%(126 / 283)$ & 2.34 & 0.13 \\
\hline $\begin{array}{l}\text { If you/they were prescribed any medication for a mental health problem, was its purpose, benefits and/or side } \\
\text { effects fully explained? (definitely/to some extent/a little) }\end{array}$ & $73 \%(169 / 233)$ & $72 \%(290 / 405)$ & 0.06 & 0.80 \\
\hline $\begin{array}{l}\text { If you/they were admitted as a hospital inpatient for treatment of a mental health problem, did staff attend to } \\
\text { your/their physical health needs in a timely manner? (definitely/to some extent/a little) }\end{array}$ & $64 \%(85 / 132)$ & $71 \%(143 / 201)$ & 1.68 & 0.20 \\
\hline $\begin{array}{l}\text { Sometimes, one health professional will say one thing and another health professional will say something quite } \\
\text { different. Did this happen to you? (not often/never) }\end{array}$ & $45 \%(69 / 153)$ & $52 \%(142 / 273)$ & 1.88 & 0.17 \\
\hline Did you have enough say in decisions about your/their care and treatment? (definitely/to some extent) & $62 \%(153 / 246)$ & $70 \%(301 / 430)$ & 4.32 & $<0.05$ \\
\hline Has your/their diagnosis been discussed with you? (definitely/to some extent) & $81 \%(199 / 246)$ & $80 \%(346 / 430)$ & 0.02 & 0.89 \\
\hline
\end{tabular}

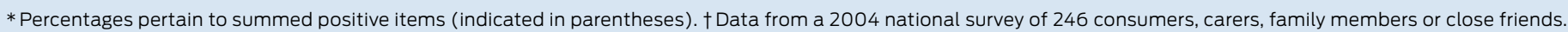
‡Data from a 2013 national survey of 561 consumers, carers, family members or close friends. ${ }^{1}$

\begin{tabular}{|c|c|}
\hline Strategy & 5-year outcome \\
\hline $\begin{array}{l}\text { Rapid expansion of youth service } \\
\text { networks and related online } \\
\text { technologies }\end{array}$ & $\begin{array}{l}\text { Access rate for people aged } 16-25 \text { years with } \\
\text { mental illness increased to } 50 \%\end{array}$ \\
\hline $\begin{array}{l}\text { Revise supported employment } \\
\text { services }\end{array}$ & $\begin{array}{l}\text { Proportion of people with mental illness in } \\
\text { employment increased to } 50 \%\end{array}$ \\
\hline $\begin{array}{l}\text { Finance enhanced primary care for } \\
\text { comorbid mental and physical health } \\
\text { care, with an emphasis on smoking } \\
\text { cessation }\end{array}$ & $\begin{array}{l}5 \text {-year increase in life expectancy of people } \\
\text { with mental illness }\end{array}$ \\
\hline $\begin{array}{l}\text { Fund prevention as a core service, } \\
\text { particularly focusing on young people } \\
\text { of school age }\end{array}$ & $\begin{array}{l}10 \% \text { reduction in rate of onset of anxiety, depressive } \\
\text { and alcohol or other substance misuse disorders } \\
\text { in those aged } 16-25 \text { years }\end{array}$ \\
\hline $\begin{array}{l}\text { Implement effective suicide prevention } \\
\text { strategies nationally }\end{array}$ & $25 \%$ reduction in suicide rate \\
\hline
\end{tabular}

the states are focused on optimising hospital-centric services, new federal funding mechanisms and genuine innovations in health (step-up and step-down beds) and secure housing, backed by clinical supports, need to lead the way.

\section{Developing national models of mental health} and social care that would help all governments plan and arrange high-quality services and help reshape community and provider expectations.

\section{Intensifying supported employment systems for people with a mental illness. Existing employment} services are not properly resourced to find work for many people with a persistent mental illness.

\section{Financing enhanced primary care systems to} support people with persistent mental illness and physical health comorbidity. Promotion of targeted smoking cessation and active reduction of other metabolic and lifestyle risks related to premature cardiovascular disease are high priorities.

\section{Developing serious e-health infrastructure to} enhance access and drive broader system reform. Virtual care systems include assessment and monitoring of care. They can also deliver more flexible working conditions for health professionals, as well as better access, cost and equity outcomes for the public.

\section{Recognising primary and secondary prevention} strategies as core services. The capacity to deliver online primary prevention programs for anxiety and depression during the school years may be most effective. Key life skills and specific psychological learning can be incorporated into the core health and social goals of school curricula and be supervised by schools, parents and other community providers. Secondary prevention of self-harm and suicidal behaviour, alcohol or other substance misuse, other psychological disorders and physical ill health (notably premature cardiovascular disease) are major objectives for all who present for care, irrespective of formal diagnosis.

\section{Developing suicide prevention at scale. The} international evidence base for effective actions in this area has increased considerably. Taken together, research findings accumulated over the past 20 years from systematic reviews suggest that there are multiple interventions that are supported. The evidence is accumulating that these interventions may operate synergistically to lower suicide risk at the population level, and that a systems approach to suicide prevention may maximise outcomes. ${ }^{17}$ However, if we are to achieve a $25 \%$ reduction in suicide rates in 5 years and a $50 \%$ reduction in 10 years, a major planning exercise is needed to determine the size of the financial investment required and which combination of community (eg, workplace-based programs) or individual (eg, treatment of depression, access to suicide prevention online) strategies should be supported.

Competing interests: Ian Hickie is a Commissioner of the National Mental Health Commission and Chair of the Scientific Leadership Council of the Young and Well Cooperative Research Centre (CRC). He was previously a Director of headspace (Australia's National Youth Mental Health Foundation). Patrick McGorry is a Director of headspace and a member of the Scientific Leadership Council of the Young and Well CRC. John Mendoza is Chair of headspace (Maroochydore) and a board member of the Young and Well CRC. Helen Christensen is a member of the Scientific Leadership Council 
of the Young and Well CRC, was previously a member of the Australian Government's E-Mental Health Advisory Group and is the developer of a number of e-health tools, including MoodGYM.

Provenance: Not commissioned; externally peer reviewed.

1 Mendoza J, Bresnan A, Rosenberg S, et al. Obsessive hope disorder: reflections on 30 years of mental health reform in Australia and visions for the future (technical report). Caloundra: ConNetica, 2013.

2 Australian Government Department of Health and Ageing. National mental health report 2010: summary of 15 years of reform in Australia's mental health services under the National Mental Health Strategy 1993 2008. Canberra: Commonwealth of Australia, 2010. http://www.health.gov.au/internet/main/publishing. nsf/Content/58B9C24B0D74E79ACA257BF0001FEADF/\$File/report10v3.pdf (accessed Nov 2013).

3 Mental Health Council of Australia. "Not for service": experiences of injustice and despair in mental health care in Australia. Canberra: MHCA, 2005. http://www.hreoc.gov.au/disability_rights/notforservice/summary/ index.html (accessed Nov 2013)

4 Groom G, Hickie I, Davenport T. Out of hospital, out of mind! A report detailing mental health services in Australia in 2002 and community priorities for national mental health policy for 2003-2008. Canberra: Mental Health Council of Australia, 2003. http://mhca.org.au/publication/out-hospital-out-mind (accessed Apr 2014).

5 Hickie IB, Groom GL, McGorry PD, et al. Australian mental health reform: time for real outcomes. Med J Aust 2005; 182: 401-406.

6 Council of Australian Governments. National action plan on mental health 2006-2011. Canberra: COAG, 2006. http://archive.coag.gov.au/coag_meeting_outcomes/2006-07-14/docs/nap_mental_health.pdf (accessed Nov 2013).

7 McGorry PD, Tanti C, Stokes R, et al. headspace: Australia's National Youth Mental Health Foundation - where young minds come first. Med J Aust 2007; 187 (7 Suppl): S68-S70.

8 Hickie IB, Rosenberg S, Davenport TA. Australia's Better Access initiative: still awaiting serious evaluation. Aust N Z J Psychiatry 2011; 45: 814-823.

9 Hickie IB, Pirkis JE, Blashki GA, et al. General practitioners' response to depression and anxiety in the Australian community: a preliminary analysis. Med J Aust 2004; 181 (7 Suppl): S15-S20.

10 Preti A, Cella M. Randomized-controlled trials in people at ultra high risk of psychosis: a review of treatment effectiveness. Schizophr Res 2010; 123: 30-36.

11 National Mental Health Commission. A contributing life: the 2012 national report card on mental health and suicide prevention. Sydney: NMHC, 2012. http://www.mentalhealthcommission.gov.au/media/39273/ NMHC_ReportCard_Lo-res.pdf (accessed Nov 2013).

12 Burns JM, Davenport TA, Christensen H, et al. Game on: exploring the impact of technologies on young men's mental health and wellbeing. Findings from the first Young and Well National Survey. Melbourne: Young and Well Cooperative Research Centre, 2013. http://www.yawcrc.org.au/news/article/241 (accessed Nov 2013).

13 Lawrence D, Hancock KJ, Kisely S. The gap in life expectancy from preventable physical illness in psychiatric patients in Western Australia: retrospective analysis of population based registers. BMJ 2013; 346: f2539.

14 Ferrari AJ, Charlson FJ, Norman RE, et al. Burden of depressive disorders by country, sex, age, and year: findings from the global burden of disease study 2010. PLoS Med 2013; 10: el001547.

15 Roxon N, Macklin J, Butler M. National Mental Health Reform 2011-12, Commonwealth Budget Papers 2011-12. Canberra:CanPrint Communications, 2011. http://budget.gov.au/2011-12/content/ministerial_statements/ health/download/ms_health.pdf (accessed Apr 2014).

16 Scott EM, Hermens DF, Glozier N, et al. Targeted primary care-based mental health services for young Australians. Med J Aust 2012; 196: 136-140.

17 Scott A, Guo B. For which strategies of suicide prevention is there evidence of effectiveness? World Health Organization Health Evidence Network synthesis report. Copenhagen: WHO, 2012. http://www.euro.who.int/ en/health-topics/noncommunicable-diseases/mental-health/publications/2012/for-which-strategies-ofsuicide-prevention-is-there-evidence-of-effectiveness (accessed Nov 2013). 